\title{
Red Cell Distribution Width is Early Marker for Detection of Iron Deficiency Anemia during Pregnancy
}

Bibi Sarah, Khalida Sheikh, Tazeen Shah

ABSTRACT

OBJECTIVES: To estimate the frequency of iron deficiency anemia in pregnancy and to analyzed the diagnostic value of RDW and compared it with non-anemic pregnant women.

METHODOLOGY: Descriptive / observational study at LUH Hospital Hyderabad, Sindh from April to October 2015. Total two hundred pregnant women were selected from which 100 non- anemic pregnant women as a control and 100 anemic pregnant women as experimental group were selected. Subjects were selected through non-probability purposive sampling. Blood samples were collected in bottles containing EDTA as an anticoagulant for complete blood counts. Serum iron and ferritin levels were measured. Data were analyzed using SPSS v.16. Chi Square \& Student t-test applied.

RESULTS: MeantSD RDW in anemic and non-anemic pregnant women was noted as $12.83 \pm 1.03 \%$ and $17.32 \pm 3.42 \%$ respectively with highly significant $p$-value of 0.0001 . Anemia was noted in $(87 \%)$ from 100 pregnant women, and the RDW was found raised in $83 \%$ women with raised RDW, 73 women showed iron deficiency anemia, RDW showed excellent sensitivity and specificity of $92 \%$ and $84.7 \%$ respectively.

CONCLUSION: The present study reports iron deficiency in pregnant women. Raised RDW was noted in iron deficiency anemia of pregnancy. RDW showed $92 \%$ sensitivity and $84.7 \%$ specificity for predicting iron deficiency anemia of pregnancy; hence it may prove of diagnostic and predictive value in clinical practice. It is concluded that the RDW is inexpensive compared to iron profile testing, hence it may be used as initial screening tools in iron deficiency of pregnancy.

KEY WORDS: Red cells distribution width, Pregnancy, Anemia

This article may be cited as: Sarah B, Sheikh K, Shah T. Red Cell Distribution Width is Early Marker for Detection of Iron Deficiency Anemia during Pregnancy. J Liaquat Uni Med Health Sci. 2018;17(03):165-9. doi: 10.22442/jlumhs.181730571

\section{INTRODUCTION}

The hemoglobin concentration and low hemoglobin within red blood cells are the most widely identified hematological abnormality ${ }^{1}$ and associated with adverse pregnancy outcome ${ }^{2}$. During 8-10 week of gestation the red blood cell mass begins to increase $20-30 \%(250-450 \mathrm{ml})$ as compared to non pregnant ladies so the need of iron increases.

In normal pregnancy the erythropoietin levels increase by $50 \%$ and levels may fluctuate during complicated pregnancy. Increases levels of erythroprotein enhance the red cell mass which to some extent supports the higher metabolic requirement for oxygen ${ }^{3}$. A cut off value of $30-70 \mathrm{~mm}$ first hour reading (FHR) for erythrocyte sedimentation rate in normal pregnancy ${ }^{4}$.

Anemia is most common disorder during pregnancy and it is defined as hemoglobin $<10.5 \mathrm{~g} / \mathrm{dl}$ in pregnancy ${ }^{3}$. Its prevalence, etiology and its severity varies among different populations. The prevalence of iron deficiency anemia, (IDA) is $35 \%$ for nonpregnant women and $51 \%$ for pregnant women world wide ${ }^{5}$. In developed countries the anemia in pregnancy is about $18 \%$ whereas $35-75 \%$ is found with an average of $56 \%$ in developing countries ${ }^{6,7}$. Anemia during pregnancy has been reported to be associated with cardiac failure, hemorrhage, infection, pre-eclampsia leading to death of pregnant women. Its effect on new born include intra-uterine growth retardation, low birth weight, anemia and increases the morbidity and mortality ${ }^{5,6}$. New Factor of RDW is assessed by hematology for measurement of $C B C$ count. RDW gives us a sign of early changes in RBCs, associated with IDA. Hence, the CBC can be utilized as a simple and rather cheap test to identify IDA through the RDW ${ }^{8}$. RDW can detect changes and small variations in red cell among different populations ${ }^{9}$.

An arithmetic measure of the changeability in the size of circulating erythrocytes, estimated throughout a typical complete blood count, is termed as RDW ${ }^{10}$. Usually, red blood cells have typical size, but disorders cause erythropoiesis or increased damage cause larger heterogeneity in size and a higher 
$\mathrm{RDW}^{16}$. It can be used as a indicator of bone marrow dysfunction, inflammation or nutritional deficiencies, or may characterize an event of the pathological process $^{12}$. Red cell distribution width (RDW) is a marker for deregulated erythropoiesis and is elevated in microcytic hypochromic anemia, macrocytic anemia, and myelodysplasias ${ }^{13}$.

The present study is proposed to analyze the role of RDW in diagnosing IDA in pregnancy, and to present facts on RDW in anemia of pregnancy as a simple inexpensive diagnostic tool.

\section{METHODOLOGY}

Descriptive / observational study with Purposive (Non Probability) sampling technique at the Department of Physiology in collaboration with Department of Obstetrics and Gynecology, Unit III, and Diagnostic and Research Lab, Liaquat University Medical and Health Sciences Hospital Jamshoro/Hyderabad, Sindh from April to October 2015. Total two hundred pregnant women were selected from which 100 nonanemic pregnant women as a control and 100 anemic pregnant women as experimental group were selected. Subjects were selected through nonprobability purposive sampling. Blood samples were collected in bottles containing EDTA as an anticoagulant for complete blood counts. Serum iron and ferritin levels were measured. Data were analyzed using SPSS v.16, using student's t-test and Chi-square test were applied and $p$ value of $\leq 0.05$ was taken as statistically significant.

Inclusion criteria: Pregnant women Anemic /nonanemic (>28 weeks of gestation), Age limit 25-50 years. Exclusion criteria: Twin babies, Diabetes mellitus, Systemic hypertension, pulmonary tuberculosis, Pregnancy induce hypertension, HELLP syndrome (hemolysis elevated liver enzymes low platelet count), and other systemic problems.

\section{DATA COLLECTION PROCEDURE}

A detailed patient history regarding duration, and symptoms related to the pregnancy was noted. The data was collected on a structured proforma. Following laboratory investigations were performed.

\section{COMPLETE BLOOD COUNT (CBC)}

$5 \mathrm{ml}$ of blood samples was collected from each participant by venipuncture and transfer in EDTA containing test tubes as an anticoagulant and were processed on automatic hematoanalyzer, Sysmex $\mathrm{Xn}-1000$. The following blood indices and parameters were studied in detail. Hematocrit (\%), hemoglobin ( $\mathrm{gm} / \mathrm{dL}$ ), RBC(million/uL), MCHC (Mean corpuscular hemoglobin concentration as \%), $\mathrm{MCH}$ (Mean corpuscular hemoglobin as $\mathrm{pg} / \mathrm{dl}$ ), MCV
(Mean corpuscular volume as femtoliter), and Red cell Distribution width (\%).

\section{MEASUREMENT OF IRON PROFILE AND FERRITIN}

The blood was collected \& stored in a clean plain bottle. Analysis for the serum iron \& TIBC was done on COBAS 600. The serum ferritin levels were measured by COBAS e 411 .

\section{DATA ANALYSIS.}

SPSS version 16 was used for data analysis. The quantitative variables were analyzed as mean $\pm S D$ (age, RBC, counts, etc) using student's t-test. Frequency and $\%$ were presented for variables using Chi-square test. A p-value $\leq 0.05$ was taken as statistically significant.

\section{RESULTS}

Total 200 pregnant women included in this study and divided into two groups. 100 non- anemic pregnant women as a control and 100 were anemic pregnant women as experimental group were selected. The age of control group was noted as $26.53 \pm 1.85$ years while as compared to the cases subjects were $35.39 \pm 7.28$ years. Hemoglobin was $11.82 \pm 1.03 \mathrm{~g} / \mathrm{dl}$ in control subjects while as compared to cases subjects it was $7.67 \pm 1.46 \mathrm{~g} / \mathrm{dl}$. RBC counts, hematocrit, $\mathrm{MCV}, \mathrm{MCH}, \mathrm{MCHC}$ and red blood cell distribution width (RDW) are shown in table 1. All of above variable showed significant difference $(p<0.05)$.

Serum iron, total iron binding capacity (TIBC) and serum ferritin in subjects with normal $\mathrm{Hb}$ and anemia were noted as $111.84 \pm 35.73$ vs. $63.05 \pm 32.94 \mu \mathrm{g} / \mathrm{dl}$, $292.30 \pm 47.82$ vs. $482.58 \pm 130.57 \mu \mathrm{g} / \mathrm{dl}$ and $46.12 \pm 22.30$ vs. $38.57 \pm 17.47 \mathrm{ng} / \mathrm{dl}$ respectively. Normal Fe, TIBC and ferritin were noted in $27 \%, 32 \%$ and $30 \%$ of subjects respectively. Low Fe, high TIBC and low ferritin were noted in $73 \%, 68 \%$ and $70 \%$ subjects respectively. Iron, TIBC and ferritin are sown in table 2 and graphs 2 respectively.

\section{RED BLOOD CELL DISTRIBUTION WIDTH (RDW)}

Mean \pm SD RDW in normal and anemic subjects was noted as $12.83 \pm 1.03$ and $17.32 \pm 3.42 \%$ respectively $(p=0.0001)$ (table 1$)$, of 87 anemic pregnant women, the RDW was elevated in 83 , of which 73 subjects showed severe iron deficiency. RDW presented specificity of $92 \%$ and $84.7 \%$ respectively.

Linear regression analysis model of RDW and serum iron is shown in table 3 . Coefficient was found as 19.98, this indicates the cut point indication for the iron deficiency. Scatter plot shows in graph 3 the linear regression analysis of RDW as dependent variable for prediction of iron deficiency anemia. 
Bibi Sarah, Khalida Sheikh, Tazeen Shah

TABLE I:

AGE, HEMOGLOBIN, HEMATOCRIT, RBC COUNTS AND RBC INDICES OF STUDY POPULATION

\begin{tabular}{|l|r|r|r|r|}
\hline \multirow{2}{*}{ Variables } & \multicolumn{1}{|c|}{ Group A } & \multicolumn{1}{c|}{ Group B } & \multirow{2}{*}{ t-value } & p-value \\
\cline { 2 - 3 } & \multicolumn{1}{c|}{ Mean \pm SD } & Mean \pm SD & & \\
\hline Age (years) & $26.53 \pm 1.85$ & $35.39 \pm 7.28$ & 13.6 & 0.001 \\
\hline $\begin{array}{l}\text { Hemoglobin } \\
\text { (g/dl) }\end{array}$ & $11.82 \pm 1.03$ & $7.67 \pm 1.46$ & 19.83 & 0.0001 \\
\hline Hematocrit(\%) & $40.04 \pm 2.15$ & $31.94 \pm 3.28$ & 18.59 & 0.0001 \\
\hline $\begin{array}{l}\text { RBC counts } \\
\text { (x10 })\end{array}$ & $3.69 \pm 0.50$ & $3.05 \pm 0.55$ & 14.35 & 0.01 \\
\hline MCV (fl) & $94.84 \pm 13.48$ & $62.49 \pm 12.45$ & 15.59 & 0.001 \\
\hline MCH (pg/dl) & $32.46 \pm 2.36$ & $23.01 \pm 3.61$ & 21.45 & 0.0001 \\
\hline MCHC (\%) & $33.30 \pm 1.84$ & $22.85 \pm 4.05$ & 33.15 & 0.0001 \\
\hline RDW (\%) & $12.83 \pm 1.03$ & $17.32 \pm 3.42$ & 60.75 & 0.0001 \\
\hline
\end{tabular}

GRAPH I:

AGE, HEMOGLOBIN, HEMATOCRIT, RBC COUNTS AND RBC INDICES OF STUDY POPULATION

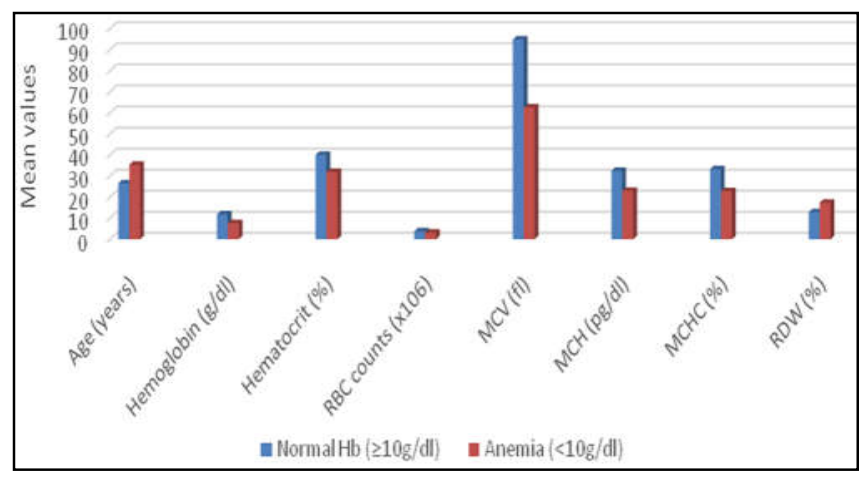

TABLE II: SERUM IRON, TOTAL IRON BINDING CAPACITY (TIBC) AND SERUM FERRITIN IN STUDY SUBJECTS

\begin{tabular}{|l|c|c|r|r|}
\hline \multirow{2}{*}{ Variables } & Group A & Group B & \multirow{2}{*}{ t- value } & \multirow{2}{*}{ p-value } \\
\cline { 2 - 5 } & Mean \pm SD & Mean \pm SD & & \\
\hline Iron $(\mathrm{Fe})(\mu \mathrm{g} / \mathrm{dl})$ & $111.84 \pm 35.73$ & $63.05 \pm 32.94$ & 48.0 & 0.0001 \\
\hline TIBC $(\mu \mathrm{g} / \mathrm{dl})$ & $292.3 \pm 47.82$ & $482.58 \pm 130.75$ & 20.84 & 0.0001 \\
\hline Ferritin $(\mathrm{ng} / \mathrm{dl})$ & $46.12 \pm 22.30$ & $38.57 \pm 47.47$ & 34.0 & 0.035 \\
\hline
\end{tabular}

GRAPH II: SERUM IRON, TOTAL IRON BINDING CAPACITY (TIBC) AND SERUM FERRITIN IN STUDY SUBJECTS

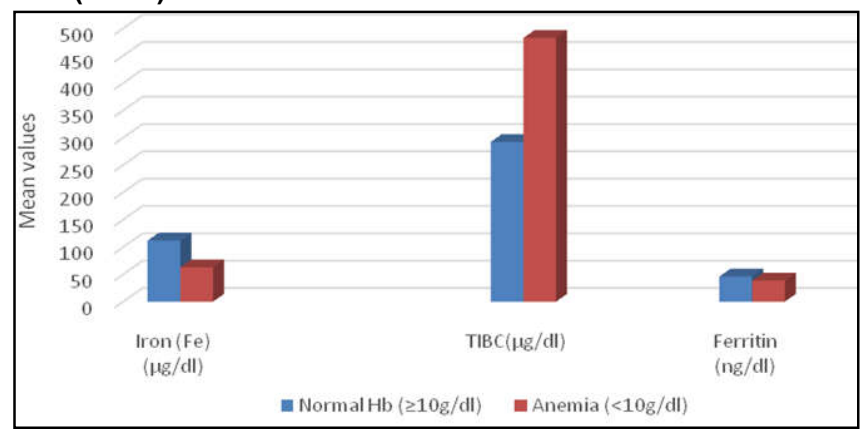

TABLE III: ANALYSIS OF VARIANCE (ANOVA)

\begin{tabular}{|c|l|c|c|c|c|c|}
\hline \multicolumn{2}{|c|}{ Model } & $\begin{array}{c}\text { Sum of } \\
\text { Squares }\end{array}$ & Df & $\begin{array}{c}\text { Mean } \\
\text { Square }\end{array}$ & F & p-value \\
\hline \multirow{3}{*}{1} & Regression & 295.86 & 1 & 295.86 & 30.44 & $0.0001^{\mathrm{b}}$ \\
\cline { 2 - 8 } & Residual & 952.33 & 98 & 9.71 & & \\
\cline { 2 - 8 } & Total & 1248.20 & 99 & & & \\
\hline
\end{tabular}

a. Dependent Variable: RDW (\%)

b. Predictors: (Constant), $\mathrm{Fe}(\mu \mathrm{g} / \mathrm{dl})$

GRAPH III: SCATTER PLOT SHOWING

DISTRIBUTION OF RDW AS DEPENDENT

VARIABLE IN IRON DEFICIENCY ANEMIA

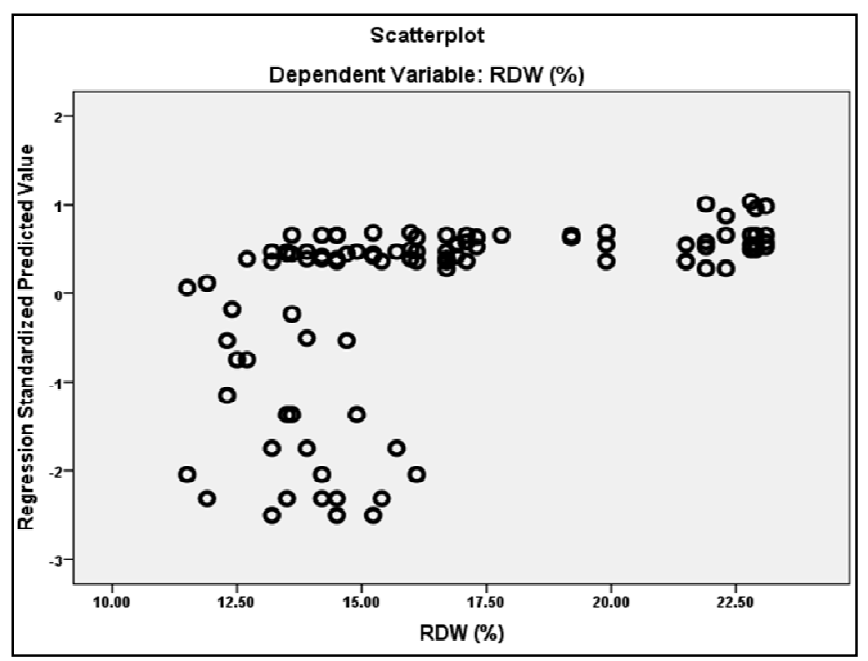

\section{DISCUSSION}

The present study was conducted in Hyderabad, Sindh which determined the RDW in iron deficiency anemia of pregnancy and its predictive value. IDA is one of the commonest nutritional problems. About 30$70 \%$ population of developing countries is suffering from the nutritional problems ${ }^{1,15}$.

In present study, the RDW was found elevated in IDA of Pregnancy. The mean \pm SD RDW in normal and anemic subjects was noted as $12.83 \pm 1.03$ and $17.32 \pm 3.42 \%$ respectively $(p=0.0001)$. Of 100 experimental subjects, $83 \%$ showed a high RDW while $17 \%$ showed normal RDW. A negative linear association was observed between RDW and serum iron levels. Out of 87 anemic pregnant women, the RDW was elevated in 83 , of which 73 subjects showed severe iron deficiency.

In present study, the RDW showed a sensitivity and specificity of $92 \%$ and $84.7 \%$ respectively for iron deficiency at cut off point of $19.98 \%$ in linear regression model. Above findings are in full comparison study reported by Abdelrahman EG $2012^{18}$ evaluated 100 anemic patients, and reported sensitivity of $92.1 \%$ 
and specificity of $90.9 \%$ for RDW in detecting iron deficiency.

Another study from Bangladesh Sultana GS $2011^{6}$ has reported sensitivity and specificity of 61.3 and 92.5 respectively $(p<0.0001)$ for $\mathrm{RDW}$ in iron deficiency anemia. Our finding of specificity is a comparable finding to above study; however, the sensitivity of 61.3 reported by Al-Farsi SH $2014^{4}$ is in contrast to present study had reported $81.0 \%$ and $53.4 \%$ sensitivity and specificity respectively at an RDW cut-off value of $17.4 \%$ for predicting microcytic hypochromic anemia. Finding of sensitivity of above study is close to our findings but the specificity is in full contradistinction to present and previous studies ${ }^{16}$

-18 . In present study the RBC indices were counted. MCV as normal, low and high was noted in 17, 79 and $4 \%$ of subjects respectively $(p=0.0001)$. This shows elevated MCV was also noted in 4 cases. Normal, low and high $\mathrm{MCH}$ and $\mathrm{MCHC}$ were noted as $18 \%, 79 \%$ and $3 \%$ respectively $(p=0.0001)$.

Our findings of RBC indices the $\mathrm{MCV}, \mathrm{MCH}$ and $\mathrm{MCHC}$ are in comparison to Matos JF $2015^{14}$. has suggested diagnostic utility of RDW for distinction between microcytosis of IDA and thalassemia. Sahli CA et $\mathrm{al}^{12}$ reported that the RDW was elevated in thalassemia minor and IDA patients.

A previous study from south Ethiopia Kefiyalew $F$ $2014^{15}$ concluded that the RDW, as alone, cannot discriminate correctly microcytic hypochromic anemia of iron deficiency and other causes. However, elevated RDW of above study is in favor of our present study. Besides this study, Matos JF $2015^{14}$ reported of RDW as of no diagnostic value in differentiating various causes of microcytic anemias.

A previous study of Abdelrahman EG $2012^{18}$ has reported on the presentation of RDW in the diagnosis of IDA and he was also using serum ferritin as a gold standard. The specificity and positive or negative predictive value of RDW was reported as $43.8 \%$, $73.7 \%, 41.0 \%$, and $76.0 \%$ respectively. Another study, conducted on pregnant women, showed RDW (cut off value $\geq 15 \%$ ) revealed sensitivity and specificity of $46.8 \%$ and $95.7 \%$ respectively ${ }^{19}$. Specificity of 95.7 of above study is a comparable finding to our present study.

Avcioglu SN $2015^{20}$ studied 102 pregnant women with pre-eclampsia and 98 pregnant women without preeclampsia as controls. Red blood cell indices the $\mathrm{MCV}, \mathrm{MCH}, \mathrm{MCHC}$ and RDW were determined. The RDW in pre-eclampsia was found to be very high median $15 \%$ (range 13.8-17.45\%) compared to controls - median $13.9 \%$ (range $13-15.6 \%)(p<0.01)$. We are of opinion that the RDW, although nonspecific, but is found elevated in IDA of different types such as pregnancy and is supported by previous studies as discussed above.

The confines of the present study are small sample size and falsely raised serum ferritin as pregnant women might be suffering from subclinical infections which might yield false results. RDW was not differentiated in various trimesters of pregnancy and values for local population are non-existent. Microcytic anemia of other causes such as thalassemia minor were not screened which is very common entity in our population.

Our present study does show in the good light of likelihood findings that the RDW may prove helpful as a initial screening tool, if not diagnostic, it may guide to proper work up for Iron deficiency of pregnancy in poor population which cannot afford expensive investigations.

\section{CONCLUSION}

The present study reports an elevated sensitivity $(92 \%)$ and specificity $(84.7 \%)$ of RDW for prediction of iron deficiency anemia. In the present study $P$ value is $<0.001$, which is strongly significant. So iron deficiency anemia does affect RDW and it can predict the iron deficiency anemia.

\section{REDCOMMENDATIONS}

Further studies are recommended to confirm the findings of our present study, if RDW becomes the proven as screening marker of iron deficiency anemia; this will benefit the poor subjects of the country. Also reference values of local population need to be settled as currently we are using western countries reference values which may not be authentic for indigenous population of the country.

\section{ACKNOWLEDGEMENT}

Authors thanks to all participant who cooperate during study and special thanks for Department of Obstetrics and Gynecology, Unit III, and technical staff of Diagnostic and Research Lab, Liaquat University Medical and Health Sciences who helped us during analysis.

\section{REFERENCES}

1. Short MW, Domagalski JE. Iron deficiency anemia: evaluation and management. Am Fam Physician 2013; 87(2): 98-104.

2. Tameika RJ, Reid HL, Mullings AM. Are published standards for hematological indices in pregnancy applicable across populations: an evaluation in healthy pregnant Jamaican women. BMC Pregnancy Childbirth 2008; 8:8. doi: 10.1186/14712393-8-8. 
3. Paidas MJ, Hossain N. Hematologic changes in pregnancy. In: Paidas MJ, Hossain N, Shamsi TS, Rodger MA, Langhoff-Roos J, Lockwood CJ. Hemostasis and Thrombosis in Obstetrics and Gynecology 2011:12-34.

4. Al-Farsi SH, Al-Khabori MK, Al-Hunieni MN, Al-Riyami NM. Fetal outcomes in pregnant women with sickle cell disease. Saudi Med J 2014; 35(5): 472-476.

5. Manning E, Corcoran P, O'Farrell IB, de Foubert $\mathrm{P}$, Drummond L, McKernan J, et al. on behalf of the Severe Maternal Morbidity Group. Severe Maternal Morbidity in Ireland Annual Report 2014. Cork: National Perinatal Epidemiology Centre, 2016.

6. Sultana GS, Haque SA, Sultana $T$, Rahman $Q$, Ahmed AN. Role of red cell distribution width (RDW) in the detection of iron deficiency anemia in pregnancy within the first 20 weeks of gestation. Bangladesh Med Res Counc Bull 2011, 37 (3):102-105.

7. Adam I, Ahmed S, Mahmoud MH, Yassin MI. Comparison of HemoCue ${ }^{\circledR}$ hemoglobin-meter and automated hematology analyzer in measurement of hemoglobin levels in pregnant women at Khartoum hospital, Sudan. Diagn Pathol 2012; 7:30.

8. Pascual-Figal DA, Bonaque JC, Redondo B, Caro C, Manzano-Fernandez S, Sanchez-Mas J, et al. Red blood cell distribution width predicts long-term outcome regardless of anaemia status in acute heart failure patients. Euro $\mathrm{J}$ Heart Fail 2009; 11(9):840-846. doi: 10.1093/eurjhf/hfp109.

9. Pasricha SR, Drakesmith H, Black J, Hipgrave D, Biggs BA. Control of iron deficiency anemia in low -and middle-income countries. Blood 2013; 121 (14):2607-17. doi: 10.1182/blood-2012-09453522.

10. Dunn L, Prior T, Kumar S. Poster Abstracts of the ISPD $18^{\text {th }}$ International Conference on Prenatal Diagnosis and Therapy. Prenat Diagn 2014; 34 (suppl 1):22-86. doi.10.1002/pd4425.

11. Milman, $\mathrm{N}$. Oral iron prophylaxis in pregnancy: $\mathrm{N}$ ot too little and not too much. J of Pregnancy 2012; 514345: 1-8. Doi.10.1155/2012/514345.

12. Sahli CA, Bibi A, Ouali F, Fredj SH, Dakhlaoui B,
Othmani $\mathrm{R}$, et al. Red cell indices: differentiation between $\beta$-thalassemia trait and iron deficiency anemia and application to sickle-cell disease and sickle-cell thalassemia. Clin Chem Lab Med 2013; 51(11): 2115-24. doi: 10.1515/cclm-2013-0354.

13. Pavord S, Myers B, Robinson S, Allard S, Strong J, Oppenheimer, C; British Committee for Standards in Haematology. UK guidelines on the management of iron deficiency in pregnancy. $\mathrm{Br} J$ Haematol. 2012; 156(5): 588-600. Erratum in $\mathrm{Br} \mathrm{J}$ Haematol 2012; 158(4):559.

14. Matos JF, Borges K, Fernades A, Faria J, Carvalho M. RDW as differential parameter between microcytic anemias in "pure" and concomitant forms. J Bras Patol Med Lab [online] 2015; 51 (1):22-27. Doi: http://dx.doi.org/10.5935/16762444.20150005.

15. Kefiyalew F, Zemene E, Asres Y, Gedefaw L. Anemia among pregnant women in Southeast Ethiopia: prevalence, severity and associated risk factors. BMC Res Notes 2014; 7: 771. doi: 10.1186/1756-0500-7-771.

16. Chang S, Zeng L, Brouwer ID, Kok FJ, Yan H. Effect of iron deficiency anemia in pregnancy on child mental development in rural China. Pediatrics 2013; 131(3):e755-63. doi: 10.1542/ peds.2011-3513.

17. Zhang $Y$, Zhang $W$, Wang S, Wang C, Xie J, Chen $X$, et al. Detection of human erythrocytes influenced by iron deficiency anemia and thalassemia using atomic force microscopy. Micron 2012; 43:1287-1292.

18. Abdelrahman EG, Gasim GI, Musa IR, Elbashir LM, Adam I. Red blood cell distribution width and iron deficiency anemia among pregnant Sudanese women. Diagnostic Pathology 2012; 7:168.

19. Casanova B, Sammel MD, Macones GA. Development of a clinical prediction rule for iron deficiency anemia in pregnancy. Am $\mathrm{J}$ Obstet Gynecol 2005; 193: 460-66. doi: 10.1016/ j.ajog.2004.12.008.

20. Avcıoğlu SN, Sezer SD, Altınkaya SO, Küçük M, Ömürlü IK, Yüksel H. Erythrocyte Indices in Patients with Preeclampsia. Meandros Med Dent J 2015; 16:35-42.
AUTHOR AFFILIATION:

Dr. Bibi Sarah

Senior Lecturer, Department of Physiology

Liaquat University of Medical \& Health Sciences

(LUMHS), Jamshoro, Sindh-Pakistan.
Dr. Khalida Sheikh

Associate Professor, Department of Physiology

LUMHS, Jamshoro, Sindh-Pakistan.

Dr. Tazeen Shah (Corresponding Author)

Assistant Professor, Department of Physiology

LUMHS, Jamshoro, Sindh-Pakistan.

Email: shahtazeen@yahoo.com 